\title{
Geometry of Chemical Beam Vapour Deposition System for Efficient Combinatorial Investigations of Thin Oxide Films: Deposited Film Properties versus Precursor Flow Simulations.
}

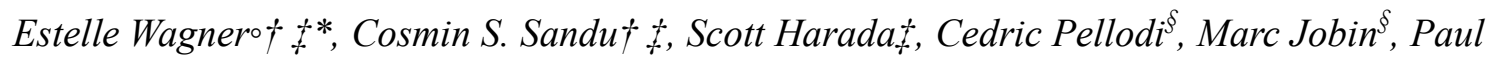
Muralt $^{\perp}$ and Giacomo Benvenuti $† \neq$

\section{Supporting Information}

\section{A-Flow simulations in the case of tilted sources:}

The flow simulation in case the Knudsen sources are tilted of an angle $\Phi$ becomes (with same notation as Figure 2):

Equation 1 bis. Flow at substrate point $M$ from source $S_{i}$

$r \times \cos \left(\alpha_{i}-\beta\right)>R+\frac{h}{\tan \Phi}, F_{\text {surf }}\left(S_{i}\right)=0$

Otherwise $F_{\text {surf }}\left(S_{i}\right)=\mathrm{C} \times \frac{I_{o}}{\pi} \frac{h \times\left(R \times \sin \Phi-r \times \sin \Phi \times \cos \left(\alpha_{i}-\beta\right)+h \times \cos \Phi\right)}{\left(R^{2}+r^{2}+h^{2}-2 R r \times \cos \left(\alpha_{i}-\beta\right)\right)^{2}}$

Equation 2 bis. Fraction of emitted molecules from source $S_{i}$ that reach the substrate.

$E f f=0.5 \times\left[\begin{array}{c}\cos \Phi \times\left(1+\frac{r_{s u b}^{2}-R^{2}-h^{2}}{\sqrt{h^{4}+R^{4}+r_{s u b}^{4}+2 h^{2} R^{2}+2 h^{2} r_{s u b}^{2}-2 R^{2} r_{s u b}^{2}}}\right) \\ +\frac{h}{R} \times \sin \Phi \times\left(-1+\frac{r_{s u b}^{2}+R^{2}+h^{2}}{\sqrt{h^{4}+R^{4}+r_{s u b}^{4}+2 h^{2} R^{2}+2 h^{2} r_{s u b}^{2}-2 R^{2} r_{s u b}^{2}}}\right.\end{array}\right]$

Equation 4 bis. Flow at substrate point $M$ from a large number of sources $S_{i}$ on the ring $F_{\text {surf }}($ ring $)=\mathrm{C} \times \frac{I_{o} \times N}{\pi} \times h \times \frac{h \times \cos \Phi \times\left(h^{2}+R^{2}+r^{2}\right)+R \times \sin \Phi \times\left(h^{2}+R^{2}-r^{2}\right)}{\left(h^{4}+R^{4}+r^{4}+2 h^{2} R^{2}+2 h^{2} r^{2}-2 R^{2} r^{2}\right)^{3 / 2}}$ 
A typical reflectometry spectrum measured to realize the thickness map shown in Figure 4 is presented in Figure S1 (blue curve) with the model curve (in red) fitted to estimate the thickness (based on the optical indexes of pure $\mathrm{TiO}_{2}$ anatase phase).

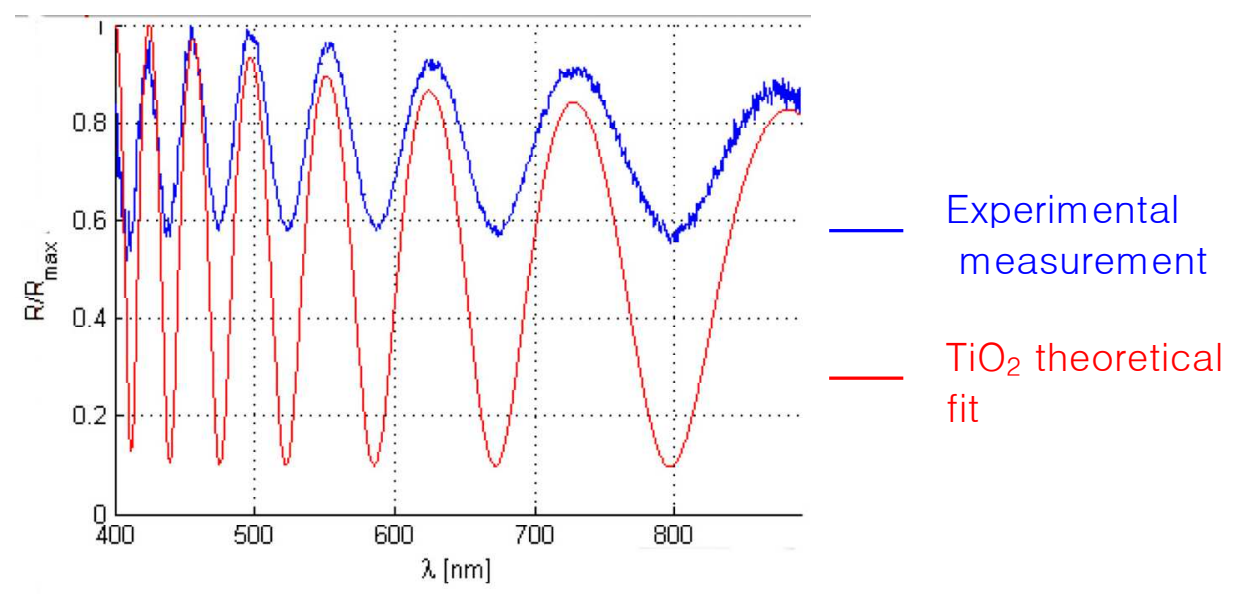

Figure S1- Typical reflectivity measurement considered for the thickness map of the $\mathrm{Nb}$ doped $\mathrm{TiO}_{2}$ film presented in Figure 4. Experimental curve (in blue) is fitted with a model $\mathrm{TiO}_{2}$ curve on floated glass (in red) to determine film thickness. 

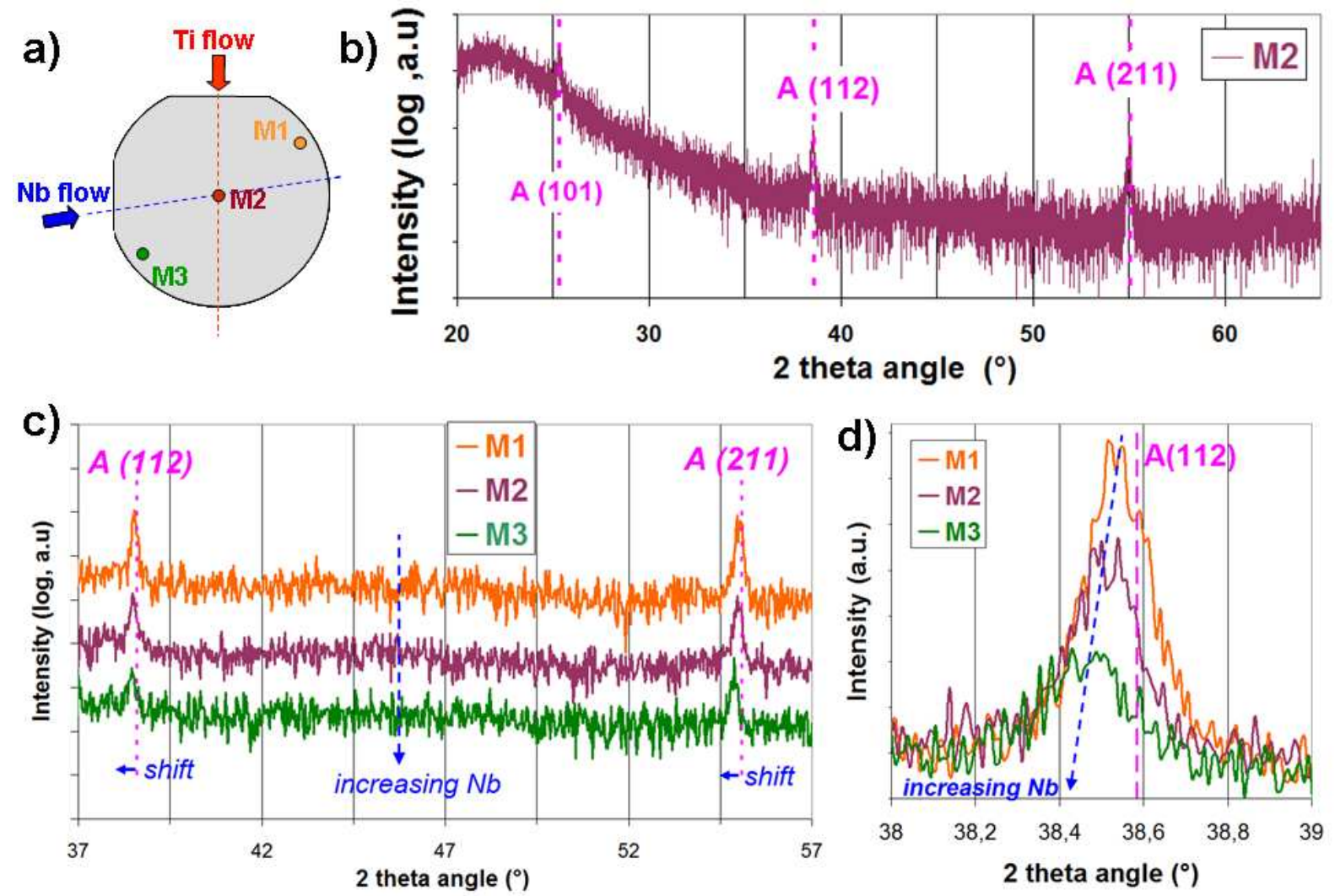

Figure S2- XRD analysis of $\mathrm{Nb}$ doped $\mathrm{TiO}_{2}$ sample presented in Figure 4. a) Location of the 3 analyzed points: $\mathrm{M} 1(2 \% \mathrm{Nb}, \approx 600 \mathrm{~nm}$ thick $), \mathrm{M} 2(4.3 \% \mathrm{Nb}, \approx 450 \mathrm{~nm}$ thick $), \mathrm{M} 3(8.6 \% \mathrm{Nb}$, $\approx 350 \mathrm{~nm}$ thick). b) Full diffractogram at point M2, with labelled peaks A for the anatase phase c) Comparison of diffraction peaks $\mathrm{A}(112)$ and $\mathrm{A}(211)$ at the 3 positions, showing a shift in peak position and decrease of peak intensity with increasing $\mathrm{Nb}$ content . d) Zoom on peak $\mathrm{A}(112)$.

XRD analysis of the binary system $\mathrm{Nb}$ doped $\mathrm{TiO}_{2}$ is presented in Figure $\mathrm{S} 2$. The film exhibits oriented anatase XRD pattern, with orientation (101), (112) and (211) (see Figure S2-b). A highly similar orientation of $\mathrm{Nb}$ doped anatase thin films deposited on glass by CVD has already been reported in literature ${ }^{84}$. No peaks are detected for any niobium based crystalline phase. It is additionally observed that increasing the doping level of $\mathrm{Nb}$ into $\mathrm{TiO}_{2}$ (from $2 \%$ in point $\mathrm{M} 1$ to $4.3 \%$ in point M2 to $8.6 \%$ in point M3) tends to shift the peaks to lower diffraction angles (see Figure S2-c and d) attesting for a substitution of $\mathrm{Ti}$ by $\mathrm{Nb}$ in the $\mathrm{TiO}_{2}$ lattice (as $\mathrm{Nb}^{4+}$ or $\mathrm{Nb}^{5+}$ ions 
have larger radius than $\mathrm{Ti}^{4+}$ ). This effect has already been reported by several other studies of $\mathrm{Nb}$ doped $\mathrm{TiO}_{2}{ }^{85}$.

\section{C-Physico-chemical characterization of the $(\mathrm{Zr}, \mathrm{Ti}, \mathrm{Nb})$ ternary oxide film (presented in Figure 5):}

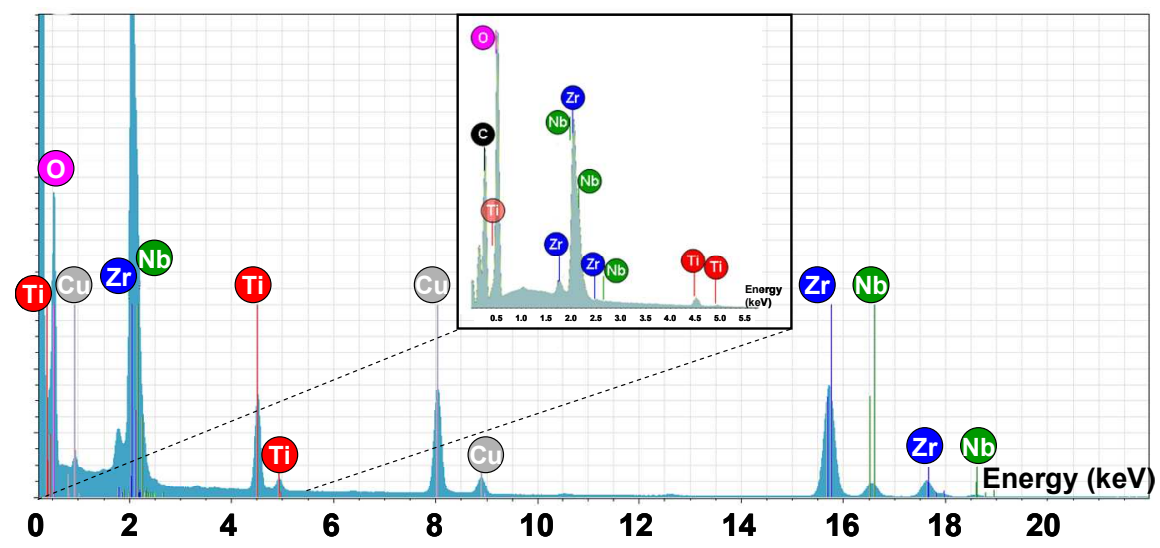

Figure S3- Typical EDX measurement on the ternary (Nb, Ti, $\mathrm{Zr}$ ) oxide film, with in insert a zoom on the low energy region.

In addition to the metallic elements $\mathrm{Nb}, \mathrm{Zr}$ and $\mathrm{Ti}$, the oxygen peak on the EDX measurement (Figure S3) confirms the film is an oxide. The low energy carbon peak corresponds to a few $\%$ of C in the analysis, but is not significant, as it may originate from the nm deposition of graphite realized on top of the film for the measurements and from carboneous surface contamination. 

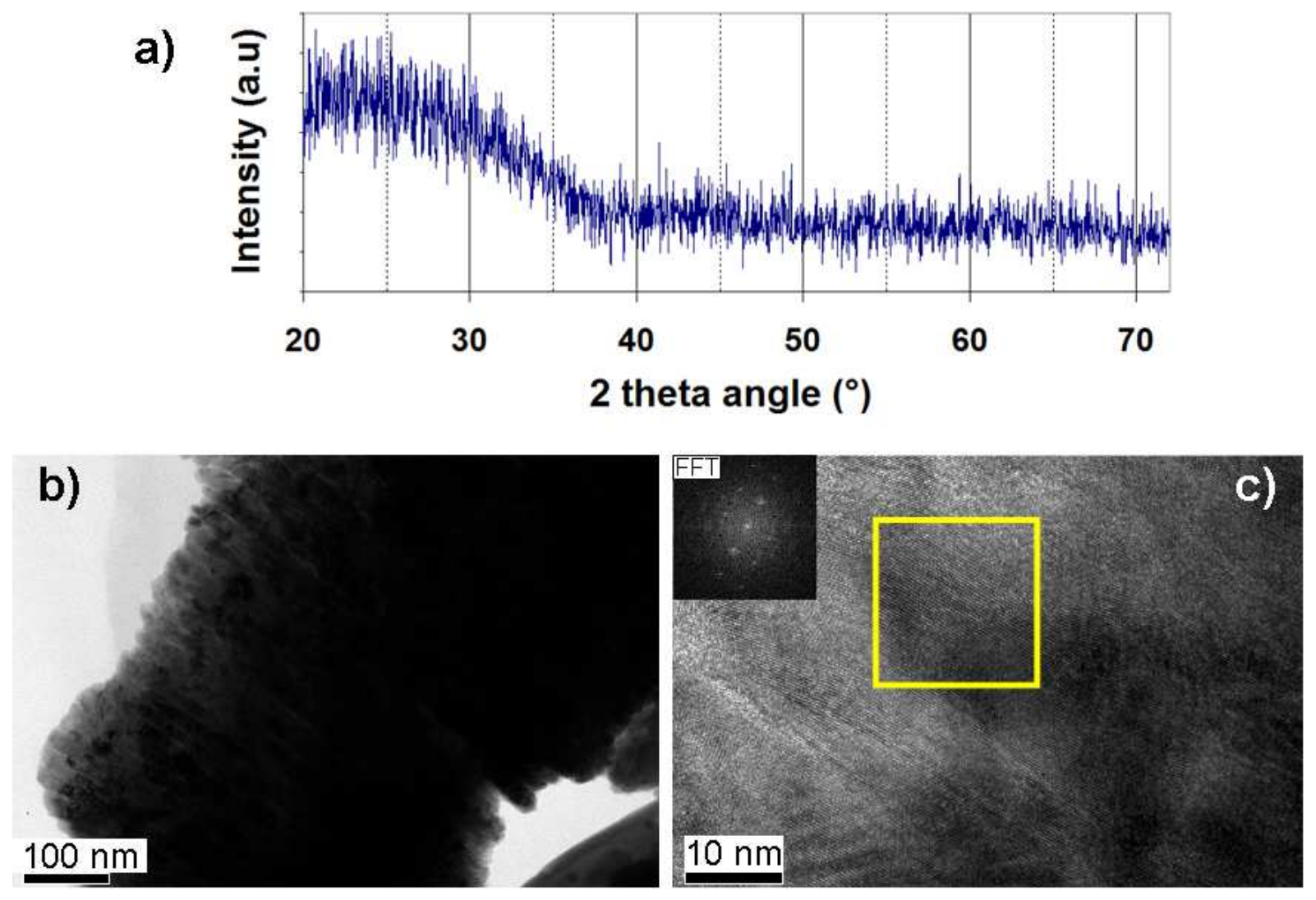

Figure S4- a) XRD analysis at the centre of the ternary sample ( $\mathrm{Nb}, \mathrm{Ti}, \mathrm{Zr}$ ) proving that the film is quasi-amorphous. b) High Resolution TEM cross section image in BF mode showing however the presence of small columnar crystallites in the $\mathrm{Zr}$ richer region (point $(-40,-20)$ on Figure $5-\mathrm{a})$ and c) High resolution TEM image at the same point showing a well crystallized structure. The FFT (Fast Fourier Transform) analysis presented in insert corresponding to the region highlighted in yellow shows interplanar distances of 3.43 and $3.12 \AA$.

\section{$\underline{\text { References }}$}

[84] Gardecka, A.J.; Goh, G.K.L.; Sankar, G.; Parkin, I.P. On the nature of niobium substitution in niobium doped titania thin films by AACVD and its impact on electrical and optical properties. $J$. Mater. Chem. A, 2015, 3(34):17755-17762.

[85] Kaleji, B.K.; Sarraf-Mamoory, R.; Fujishima, A. Influence of Nb dopant on the structural and optical properties of nanocrystalline $\mathrm{TiO}_{2}$ thin films. Mater. Chem. Phys., 2012, 132(1):210215. 